44 InterAção

\title{
REGIME INTERNACIONAL DOS POVOS INDÍGENAS: REFERÊNCIAS TEÓRICO-DESCRITIVAS
}

Felipe Moreira ${ }^{1}$

\section{Resumo}

O propósito desta contribuição é fornecer referências descritivas sobre o regime internacional dos povos indígenas. A metodologia empregada nesta pesquisa é qualitativa, com referência a fontes primárias e secundárias. $\mathrm{O}$ artigo reúne elementos da história da formação do regime internacional dos povos indígenas e elabora reflexões sobre o conteúdo do direito internacional dos povos indígenas com referência às instituições e iniciativas políticas atuais.

Palavras-chave: povos indígenas, regime internacional, direito internacional, autodeterminação.

\begin{abstract}
The purpose of this contribution is to provide descriptive references to the international regime of indigenous peoples. The methodology employed in this research is qualitative, with reference to primary and secondary sources. The article brings together elements of the history of the formation of international regime on indigenous peoples and elaborate reflections on the content of the internacional law of indigeous people with reference to the institutions and current policy initiatives.
\end{abstract}

\footnotetext{
1 Professor Associado de Direito Internacional nos cursos de Relações Internacionais, Comércio Exterior e Direito da Universidade Federal do Rio Grande - FURG. Professor Permanente do Programa de Pós-Graduação em Gerenciamento Costeiro - PPGC/FURG. Líder do Grupo de pesquisa do CNPq "A formação de ordens normativas no plano internacional". Doutor (2009) e Mestre (2004) em Relações Internacionais pela Universidade de Brasília-UnB. Scholarship Holder DAAD/CNPq (doutorado sanduíche) na Johann Wolfgang Goethe Universitaet Frankfurt am Main (2007-2009). Bacharel em Direito pela Fundação Universidade Federal do Rio Grande - FURG (2001). Estudou e pesquisou no Center for Hemispheric Defense Studies, National Defense University, Washington DC (2003), no Comitê Jurídico Interamericano da Organização dos Estados Americanos, Rio de Janeiro (2005), na Academia de Direito Internacional das Nações Unidas, Haia, Países Baixos (2009) e no European University Institute, Florença, Itália (2009). Professor do Bacharelado em Relações Internacionais (2006-2015) e no Mestrado em Sociedade e Fronteiras PPGSOF (2010-2018) do Centro de Ciências Humanas, da Universidade Federal de Roraima-UFRR. Atuou como Assessor Jurídico na Coordenação-Geral de Legislação e Normas do Ensino Superior, da Secretaria do Ensino Superior do Ministério da Educação (2002-2004) e como Coordenador de Articulação Institucional do Departamento de Recuperação de Ativos e Cooperação Jurídica Internacional, do Ministério da Justiça (2004-2005). Assessor do SciELO Brasil (CNPq, FAPESP, FapUNIFESP e BIREME) na avaliação de mérito de periódicos. Possui artigos publicados no Brasil, Argentina, Estados Unidos da América, Portugal, México e Venezuela. Áreas de interesse: Poder e Normas nas Relações Internacionais; Direito Internacional; Governança Global dos Oceanos; Legitimidade; Identidade e Relações Internacionais e Povos Indígenas e Relações Internacionais.
} 
45 InterAção

Keywords: indigenous people, international regime, international law, selfdetermination.

\section{INTRODUÇÃO}

O propósito desta contribuição é oferecer referências descritivas sobre o regime internacional dos povos indígenas. Existem resultados de pesquisas consolidadas a respeito do assunto, parte deles mencionados, ao final, nas referências. Este texto procura oferecer um panorama de fontes de pesquisa e busca situar o tema na atualidade das relações internacionais. $\mathrm{O}$ artigo reúne elementos da história da formação do regime internacional dos povos indígenas e elabora reflexões sobre os conteúdos de direitos com referência às instituições e iniciativas políticas atuais.

Este artigo poderia ser caracterizado como contribuição aos esforços historiográfico- jurídicos internacionalistas. Convergiu para este propósito, até onde se percorreu, não haver texto, neste padrão, sobre o regime (ou direito) internacional dos povos indígenas. Não constam nos objetivos deste artigo tecer avaliações críticas ou da efetividade de normas e instituições internacionais dedicadas aos povos indígenas. Também não constitui objetivo deste artigo relacionar o direito internacional dos povos indígenas com o plano jurídico latino-americano ou brasileiro, muito embora sejam feitas referências às iniciativas regionais da Organização dos Estados Americanos (OEA) e do sistema interamericano de direitos humanos. 
46 | InterAção

\section{ANTECEDENTES}

O Tratado de Tordesilhas, de 1494, e o de Saragossa, de 1529 podem ter sido as primeiras fontes de direito internacional alçadas à eficácia nos domínios ameríndios. Na Bula Inter Coetera, de 1493, o Papa Alexandre VI, manifesta o desejo que os povos originários na América, fossem dominados e convertidos: barbarica nationes deprimantur et ad fidem ipsam reducantur ${ }^{2}$. A historiografia jurídica registra que, no século XVI, povos indígenas da América foram motivo de controvérsias, com particular destaque para a obra de Francisco de Vitória (1483-1546), Juan de la Peña (1513-1565) e Francisco Suárez (1548-1617). Francisco de Vitória deixou suas aulas (relectiones) escritas, das quais, duas datadas de 1532, se referem aos povos indígenas: Sobre a descoberta dos índios (De Indis recenter inventis) e sobre as guerras da Espanha contra os povos originários (De iure belli Hispanorum in barbaros) ${ }^{3}$. Mantinha que povos indígenas deveriam ser compreendidos enquanto nações e que a guerra contra eles somente poderia ser justificada por uma causa justa ${ }^{4}$. Hoje se reconhecem os avanços teóricos e argumentativos por parte da escolástica espanhola tardia, notadamente quanto ao direito à guerra ${ }^{5}$. A Espanha mantivera a guerra com base na recusa à evangelização ${ }^{6}$. Para Francisco de Vitória, não era um argumento legítimo. Assim

\footnotetext{
2 ZIEGLER, 2007, 123.

3 ZIEGLER, 2007, 132.

${ }^{4}$ SHAW, 2003, 22.

${ }^{5} \mathrm{~A}$ este respeito, a revisão do conceito medievo de guerra justa (bellum justum) foi feita por Francisco de Vitória que acrescentou a ideia de exceção (bellum iustum ex utraque parte) de forma a haver uma guerra justa para cada parte. (ZIEGLER, 2007, 127)

6 "Therefore the Indians cannot be induced by war to believe, but rather to feign belief and reception of the Christian faith, which is monstrous and a sacrilege [...] Further, the Pope cannot make war on Christians on the ground of their being fornicators or thieves or, indeed, because they are sodomites; nor can he on that ground confiscate their land and give it to other princes; were that so, there would be daily changes of kingdoms, seeing that there are many sinners in every realm." (VITÓRIA, 2015, 01-02)
} 
47 InterAção

como Hugo Grotius antecipou, com seu De Mare Liberum (1609), ideias que ecoariam na Convenção de Montego Bay de 1982; Francisco de Vitória, com o De Indis (1532), antecipa a Convenção 169 de 1989 (Sobre Povos Indígenas e Tribais em Países Independentes).

No direito internacional contemporâneo, a atenção aos povos indígenas surge com a categoria descritiva de minorias nacionais, a qual comporta também "nações sem Estado" e grupos etnográficos7. Guillermo F. Margadant S. situa um possível início do debate sobre o direito internacional dos povos indígenas, a partir do registro, em 1953, da proposta de Sub-Comissão para a Prevenção da Discriminação e Proteção de Minorias, ramo da ora Comissão de Direitos Humanos com sugestões para a definição de minorias étnicas ${ }^{8}$. Margant sustenta que o presidente Woodrow Wilson sugerira que o Estatuto da Liga das Nações contivesse a garantia de respeito às minorias, mas a ideia não foi levada a efeito ${ }^{9}$. O Pacto da Sociedade das Nações menciona 'populações indígenas' no art. 22 que se refere aos princípios aplicados às colônias e territórios que, por causa da guerra, deixaram de pertencer à soberania de determinados países. O Pacto exige a proibição de instruir militarmente os indígenas (22. 6) e solicita que seja garantido o interesse das populações indígenas quanto aos (Estados) mandatários (22. 7).

Para além dos prolegômenos, no plano multilateral da Sociedade das Nações, a doutrina internacionalista dedicada aos povos indígenas comumente expõe o tema nos contornos da seguinte linearidade: as primeiras iniciativas de direitos humanos, o papel da Organização Internacional do Trabalho e da

\footnotetext{
7 "The category of national minorities (or what others call 'homeland minorities') includes indigenous peoples like the Inuit in Canada, Maori in New Zealand, or Sami in Scandinavia, but also includes other incorporated national groups, like the Catalans in Spain, Scots in Britain or Québécois in Canada. These later groups are sometimes called 'stateless nations' or 'ethno-national groups', to distinguish them from indigenous peoples" (KYMLICKA, 2000, 221)
}

8 MARGADANT, 1992, 148.

9 MARGADANT, 1992, 165. 
48 InterAção

Convenção 169 de 1989 e, mais recentemente, o papel da Organização das Nações Unidas (ONU), em particular a Declaração da ONU sobre o Direito dos Povos Indígenas, de 2007 (Resolução 61/295 da Assembleia Geral). Esta descrição assume o viés da historiografia jurídica, tendo como foco a legitimidade e a legalidade de direitos indígenas a partir do reconhecimento pelo sistema multilateral de Estados, o que poderia ser considerado uma análise top-down. Seria possível também falar na perspectiva indígena sobre a evolução dos direitos indígenas no plano internacional, o que poderia ser considerado uma análise botton-up, a partir de diferentes fontes e métodos. Algumas mudanças de caráter administrativo na ONU, em 2005 e 2007, devem ser observadas para bem situar o 'estado da arte' do direito internacional dos povos indígenas, no momento em que este texto é escrito. No plano regional existem espaços institucionais na OEA e no sistema americano de direitos humanos, no qual se desenvolveu um conjunto jurisprudencial dedicado aos direitos dos povos indígenas. Estes temas serão desenvolvidos gradualmente ao longo da primeira parte deste artigo.

\section{O DIREITO INTERNACIONAL DOS POVOS INDÍGENAS: NORMAS E INSTITUIÇÕES}

A Organização Internacional do Trabalho (OIT) foi a primeira organização intergovernamental a se envolver com assuntos sobre nativos e indígenas. Niezen indica que o primeiro esforço no âmbito da organização foi a Legislative Ordinance nr. 52, de 1924, que se referia às punições extremas aplicadas aos trabalhadores nas plantações no Burundi ${ }^{10}$. Não se trata de um divisor de águas, mas de um reconhecimento: "at a time when so-called natives were neither sovereign unto themselves nor nationals of colonizing states but were legally

${ }^{10}$ NIEZEN, 2003, 36. 
49 | InterAção

considered "wards"11. A OIT, ainda, sob a Liga das Nações, elaborou a Convenção 50, de 1936 (sobre o trabalho indígena), a Convenção 64, de 1939 (sobre contratos de emprego de trabalhadores indígenas) e a Convenção 65, de 1939 (sobre sanções penais a trabalhadores indígenas) ${ }^{12}$.

O primeiro conjunto normativo amplo, no plano internacional, relativo aos povos indígenas foi a Convenção 107, de 1957, da OIT, seguida pela Recomendação 104. A crítica à Convenção 107 é que muito embora ela represente a força de atores não-estatais, os encontros entre especialistas ocorreram sem participação aparente de povos indígenas; além disso, a Convenção refletira a premissa da assimilação operativa pelos núcleos políticos dominantes, no plano nacional e internacional ${ }^{13}$.

A partir dos anos sessenta, movimentos sociais dos povos indígenas passaram a participar na política internacional com demandas direcionadas às organizações intergovernamentais ${ }^{14}$. Destaca-se aqui o desenvolvimento do conceito Quarto Mundo, para se referir às "semelhanças existentes entre as múltiplas minorias aborígenes que vivem hoje no interior das fronteiras dos Estados nacionais industriais prósperos" ${ }^{15}$. Este processo foi historicamente constituído por "variáveis políticas nas relações internacionais que catalisaram a formação dos movimentos de resistência", em particular na América Latina, fenômeno este conhecido como pan-indigenismo ${ }^{16}$. Sobre este período, James

\footnotetext{
11 NIEZEN, 2003, 37.

12 MARGADANT, 1992, 166.

13 ANAYA, 2004, 54-55.

${ }^{14}$ NIEZEN, 2003, 42; BRYSK, 2000, 55ss; LE BOT, 2013, 198.

15 BORGES, 2013, 33.

16 BORGES, 2013, 40.
} 
$50 \mid$ InterAção

Anaya ${ }^{17}$ ressalta a Conferência de Organizações Não-Governamentais sobre Discriminação contra Populações Indígenas na América, realizada em Geneva em 197718. Esta Conferência teria possibilitado a articulação entre representantes indígenas de forma a reforçarem seus fundamentos com base em princípios de direitos humanos. A partir de então, organizações representativas de grupos indígenas conseguem o status consultivo junto ao Comitê Econômico e Social bem como junto à Organização dos Estados Americanos (OEA) ${ }^{19}$.

Em 1986, o Conselho de Administração da OIT convocou uma reunião de peritos para debater modificações necessárias à Convenção 107. Com a presença de representantes governamentais, de indígenas e de organizações sindicais, a reunião concluiu, em primeiro plano, que "a tendência à integração da atual Convenção é inadequada e não reflete os conceitos atuais" ${ }^{20}$. É, então, que a Convenção 169 da OIT sobre Povos Indígenas e Tribais, de 1989, passa a ser a referência normativa para tratar dos direitos indígenas no plano internacional. A Convenção 169 é a revisão da Convenção 107 de 1956²1. A OIT registra que possui 22 ratificações e nenhuma denúncia 22 . Esta Convenção será analisada na próxima

\footnotetext{
17 S. James Anaya é professor de direitos humanos na University of Arizona. Autor de "Indigenous Peoples in International Law", de 1996, que é obra de referência sobre 0 assunto tratado neste artigo. Participou na elaboração do Texto Final da Declaração das Nações Unidas sobre o Direito dos Povos Indígenas de 2007. Em 2008 foi nomeado pelas Nações Unidas o Relator Especial para a situação dos direitos humanos e liberdades fundamentais dos povos indígenas.

18 ANAYA, 2004, 57.

${ }^{19}$ ANAYA, 2004, 57.

${ }^{20}$ CUNHA, 1987, 209.

21 "Esta Convenção revisa a Convenção sobre Populações Indígenas e Tribais, de 1957." (art. 36 da Convenção 169 de 1989).

22 Os países que ratificaram com o ano da ratificação entre parênteses: Argentina (2000), Bolívia (1991), Brasil (2002), Chile (2008), Colômbia (1991), Costa Rica (1993), Dinamarca (1996), Dominica (2002), Equador (1998), Espanha (2007), Fiji (1998), Gualemala (1996), Honduras (1995), México (1990), Nepal (2007), Nicarágua (2010), Noruega (1990), Países Baixos (1998), Paraguai (1993), Peru (1994), República Centro Africana (2010) e Venezuela (2002). Fonte: http://www.ilo.org/dyn/normlex/en/. Acessado em março de 2015.
} 
51 InterAção

sessão; importa aqui localizá-la na linearidade temporal de normas e instituições internacionais.

Paralelamente aos esforços da OIT e da ONU, desenvolveu-se o conjunto normativo dos direitos humanos que passaram a ser incorporados aos argumentos jurídicos dos movimentos sociais indígenas ${ }^{23}$. Merecem referência a Declaração Universal de 1948, a Convenção contra o Genocídio de 1948, Convenção contra a Discriminação Racial de 1965 e os dois Pactos de 1966. É verdade que estes diplomas citados abrangem uma ampla dimensão de direitos e um dos desafios trazidos pela universalidade era a relação entre genocídio e etnocídio ${ }^{24}$. Outro Tratado de direitos humanos com impacto direto nas sociedades indígenas foi a Convenção da Organização para a Educação, a Ciência e a Cultura (UNESCO), relativa à luta contra as Discriminações na Esfera do Ensino, de 1960, que prevê, no artigo 5º, c, que "deve ser reconhecido aos membros das minorias nacionais o direito ao exercício das atividades docentes, emprego e ensino do próprio idioma". Também sob o alto patrocínio da UNESCO, encontra-se a Declaração de São José sobre "Etnocídio e Etnodesenvolvimento", de 1981, na qual declara-se que o "etnocídio, a saber, o genocídio cultural, é um delito de direito internacional igual ao genocídio." 25

Houve muita expectativa acerca das reformas que a ONU poderia fazer em 2005. No que diz respeito ao direito internacional dos povos indígenas, a Comissão de Direitos Humanos, ligada ao Conselho Econômico e Social ${ }^{26}$ foi abolida e substituída pelo Conselho de Direitos Humanos, com sede em Genebra,

${ }^{23}$ MARGADANT, 1992, 167.

24 "Since 1948, the debate on genocide has grown in breadth and depth, but still there is no common definition. [...] Within genocide studies, some scholars now place particular emphasis on the concept of ethnocide understood as "cultural genocide." (OETLER, 2006, 05-06)

25 CUNHA, 1987, 199.

${ }^{26}$ Com base no art. 62 (2) da Carta das Nações Unidas: "Poderá igualmente fazer recomendações destinadas a promover o respeito e a observância dos direitos humanos e das liberdades fundamentais para todos". 
52 InterAção

o qual funciona como um órgão subsidiário da Assembleia Geral27. Em 14 de dezembro de 2007, o Conselho de Direitos Humanos criou, mediante a Resolução 6/36, um Mecanismo de especialistas em direito dos povos indígenas, composto de cinco especialistas independentes, de preferência com ascendência indígena, para o mandato de três anos, renovável uma vez. O Mecanismo deve fazer um Relatório Anual ao Conselho e possui competência para desenvolver estudos e pesquisas e sugerir ao Conselho propostas a serem aprovadas, de trabalho para o Conselho 28 .

Em 1992, Guillermo Margadant indicava o projeto de uma Declaração Universal dos Povos Indígenas como resultado de um Grupo de Trabalho (Working Group) de 1981/2 e do Relatório Cobo de 198729. Antecipava uma constelação que permitiria aprovar em 1993 uma "Declaração" na Assembleia Geral da ONU, mais adiantada e progressiva do que a Convenção 169, mas sem chegar a um "futurismo radical", ao que apontava para o perigo do excesso de idealismo. Em síntese, havia reivindicações de bases concretas para dirigir demandas e eventualmente invocar autoridades que transcendessem o nível nacional ${ }^{30}$. Em 1994 a Assembleia Geral da ONU proclamou a Década dos Povos Indígenas do Mundo, de forma a promover a Declaração ${ }^{31}$.

\footnotetext{
27 DURAN, 2006, 08.

28 UNITED NATIONS, Resolution 3/36, 2007.

29 MARGADANT, 1992, 168. Sobre o Relatório Cobo: "One of the most cited descriptions of the concept of the indigenous was given by Jose R. Martinez Cobo, the Special Rapporteur of the Sub-Commission on Prevention of Discrimination and Protection of Minorities, in his famous Study on the Problem of Discrimination against Indigenous Populations. UN Doc. E/CN.4/Sub.2/1986/7 and Add. 1-4. The conclusions and recommendations of the study, in Addendum 4, are also available as a United Nations sales publication (U.N. Sales No. E.86.XIV.3). The study was launched in 1972 and was completed in 1986, thus making it the most voluminous study of its kind, based on 37 monographs." (UNO, 2004)
}

30 MARGADANT, 1992, 174 a 176.

${ }^{31}$ NIEZEN, 2003, 24. 
53 InterAção

A partir de uma diretriz da Conferência Mundial sobre Direitos Humanos de 1993 e após um período de avaliações, o Conselho Econômico e Social da ONU (ECOSOC) criou o United Nations Permanent Forum on Indigenous Issues (Resolução 2000/22, de 28 de julho de 2000), que se reuniu pela primeira vez em 2002 ${ }^{32}$. O Foro possui o mandato de aconselhar e fazer Recomendações ao ECOSOC e é composto de 16 membros especialistas independentes, para o mandato de três anos, com a possibilidade de uma reeleição ou dilação de mandato; são oito eleitos no ECOSOC a partir de indicações dos Estados e oito designados pelo Presidente do ECOSOC, a partir de consultas formais às organizações indígenas ${ }^{33}$.

Em 13 de setembro de 2007, a Assembleia Geral da ONU adota a Declaração das Nações Unidas sobre o Direito dos Povos Indígenas. A Declaração foi aprovada pela maioria de 144 países a favor, quatro votos contra - Austrália, Canadá, Nova Zelândia e Estados Unidos - e 11 abstenções Azerbaijão, Bangladesh, Butão, Burundi, Colômbia, Georgia, Quênia, Nigéria, Rússia, Samoa e Ucrânia ${ }^{34}$.

Os posicionamentos de política externa, particularmente quanto aos Estados contrários ou que se abstiveram, poderiam merecer análises as quais não participam do escopo desta contribuição. A Nova Zelândia, em 20 de abril de 2010, manifestou, mediante uma Declaração do Ministro da Justiça, apoio à

\footnotetext{
32 ANAYA, 2004, 219.

${ }^{33}$ ECOSOC, Resolution 2000/22 (1): "eight members to be nominated by Governments and elected by the Council, and eight members to be appointed by the President of the Council following formal consultation with the Bureau and the regional groups through their coordinators, on the basis of broad consultations with indigenous organizations, taking into account the diversity and geographical distribution of the indigenous people of the world as well as the principles of transparency, representativity and equal opportunity for all indigenous people..."

34 Conforme 0 registro dos votos no sítio institucional da 0NU. Fonte: http://unbisnet.un.org:8080/ipac20/ipac.jsp?profile=voting\&index=.VM\&term=ares61295. Acessado em março de 2015.
} 
$54 \mid$ InterAção

Declaração da ONU35 e assim também o Canadá, em 12 de dezembro de 2010, por meio de uma declaração do governo ${ }^{36}$. Em artigo de 2008, Megan Davis analisa a posição da Austrália quanto à Declaração e afirma que a posição do governo federal australiano dependia da coalizão política; que o governo trabalhista apoiava o termo autodeterminação, constante na Convenção 169, apesar da Austrália não a ter ratificado; que esta posição foi modificada com o governo de coalisão liberal, a partir de 1997, para a crítica à terminologia autodeterminação ${ }^{37}$, que é a posição que prevaleceu quando da votação na Assembleia Geral em 2007. Na Austrália existiam pressões sociais de ONGs pelo direito dos povos indígenas, pressões de juristas que entendem que haveria uma ruptura na coesão interna do sistema jurídico australiano ${ }^{38}$. Em 03 de abril de 2009, o governo federal australiano indicou o apoio à Declaração da ONU de 2007, muito embora persistam as resistências no plano do direito interno e das políticas públicas ${ }^{39}$. O grupo CANZUS 40 , de países que votaram contrários à

35 NEW ZEALAND, 2010. 0 ramo neozeolandês da organização internacional International Development Organisation divulgou um estudo no qual registra os efeitos da Declaração: "When New Zealand endorsed the Declaration the government made it clear that they considered the document aspirational rather than legally binding and it would only be implemented within the current legal and constitutional frameworks of New Zealand." (NEW ZEALAND, s/d).

360 Canadá fundamenta o voto contrário em 2007 da seguinte forma: "In 2007, at the time of the vote during the United Nations General Assembly, and since, Canada placed on record its concerns with various provisions of the Declaration, including provisions dealing with lands, territories and resources; free, prior and informed consent when used as a veto; self-government without recognition of the importance of negotiations; intellectual property; military issues; and the need to achieve an appropriate balance between the rights and obligations of Indigenous peoples, States and third parties." (CANADA, 2010).

37 "Foreign Minister Alexander Downer stated that it was better to use the word 'self-management' rather than 'selfdetermination', as the term 'self-determination' leaves an impression 'that we are prepared to have a separate indigenous state'" (DAVIES, 2008, 30)

38 DAVIES, 2008, 31.

39 "Despite the fact that the Australian Government reversed its position in 2009 to formally support the Declaration, the Social Justice Commissioner is concerned that the governments of Australia continue to misunderstand the relevance of the Declaration in their activities, and are unclear about their obligations in this regard." (AUSTRALIAN HUMAN RIGHTS COMISSION, 2011, 27)

40 "Indigenous observers' relationship with Chairperson-Rapporteur Chavez was fraught with difficulties from the beginning. They found him to be inconsistent and that he gave excessive weight to the objections of Canada, Australia, New Zealand and the US (the CANZUS Group) in seeking consensus on the text. These states were perceived as being obstructionist in their conduct and as persistent objectors to provisions relating to the right to self-determination and 
55 | InterAção

Declaração - ex colônias da Commonwealth - manifestaram preocupações semelhantes: conceito de autodeterminação, exploração de recursos naturais e questões territoriais relacionadas a grupos minoritários de povos indígenas. Em 16 de dezembro de 2010, quatro dias após o Canadá, o presidente Barak Obama, anunciou o apoio norte-americano à Declaração ${ }^{41}$. Em termos de dogmática jurídica, relativo aos países CANZUS, houve ato unilateral de Estado, posterior à aprovação na Assembleia da ONU; gera opinio juris, enquanto elemento subjetivo do costume, por isso, com efeitoo jurídico diferente da ratificação.

Em 19 de dezembro de 2011, a Assembleia Geral adotou a Resolução A/RES/66/142 que revela no quanto o denominado direito internacional dos povos indígenas relaciona-se com política internacional, direitos humanos e meio ambiente. Nesta Resolução, reafirma-se a Resolução 65/198, de 21 de dezembro de 2010, na qual dá-se início à realização de uma reunião plenária da Assembleia Geral, denominada de Conferência Mundial sobre Povos Indígenas. A atuação do Foro Permanente sobre Assuntos Indígenas foi decisiva para a Conferência que veio a ocorrer em 22 e 23 de setembro de 2014, sob o alto patrocínio da Assembleia Geral da ONU. Da Conferência Mundial sobre Povos Indígenas resultou a adoção da Resolução A/RES/69/2, de 25 de setembro de 2014. Esta Resolução reafirma os entrelaçamentos temáticos da anterior e assinala o alcance e a progressiva interpretação e consolidação do direito internacional dos povos indígenas no sistema multilateral da ONU. A Resolução de 2014, encoraja à ratificação da Convenção 169, mostra o comprometimento com as instituições de justiça dos povos indígenas ${ }^{42}$, convida o Conselho de Direitos Humanos à revisão

lands, territories and resources." (DAVIES, 2008, 09)

41 "[...] in April, we announced that we were reviewing our position on the U.N. Declaration on the Rights of Indigenous Peoples. And today I can announce that the United States is lending its support to this Declaration." (UNITED STATES OF AMERICA, 2010)

42 “16. We acknowledge that indigenous peoples' justice institutions can play a positive role in providing access to justice and dispute resolution and contribute to harmonious relationships within indigenous peoples' communities 
56 | InterAção

do Expert Mechanism on the Rights of Indigenous Peoples (28), manifesta de diferentes maneiras a relação entre os povos indígenas e os direitos humanos (29 e 30) e meio ambiente (34 a 36).

No plano regional americano, a OEA envidou esforços para realizar, em 1940, o Congresso Indigenista de Pátzcuaro, ocasião em que foi criado o Instituto Indigenista Interamericano ${ }^{43}$. O Instituto se tornou uma agência especializada da OEA e um recurso para consultas pelos Estados membros ${ }^{44}$. Brysk indica que muitos dos antropólogos ligados aos movimentos indígenas, em particular à dissidência antropológica iniciada no México nos anos setenta, foram diretamente associados ao Instituto ${ }^{45}$. Em 1989 a Assembleia Geral da OEA solicitou à Comissão Interamericana de Direitos Humanos que preparasse um instrumento judicial relativo aos povos indígenas que resultou no projeto de Declaração Americana sobre os Direitos dos Povos Indígenas ${ }^{46}$ o qual permanece em debate no Comitê de Assuntos Políticos e Jurídicos, em busca de consenso ${ }^{47}$. Em 1990, a Comissão Interamericana de Direitos Humanos criou a Relatoria sobre os Direitos dos Povos Indígenas devotada a promover a proteção dos direitos dos povos indígenas.

Os sistemas regionais de direitos humanos têm contribuído para o regime internacional dos direitos indígenas, contribuições estas que procedem principalmente dos sistemas africano, americano e europeu. O sistema americano

and within society. We commit ourselves to coordinating and conducting dialogue with those institutions, where they exist." (UNO, 2014)

43 MARGADANT, 1992, 168.

${ }^{44}$ ANAYA, 2004, 56.

${ }^{45}$ BRYSK, 2000, 64.

${ }^{46}$ ANAYA, 2004, 66.

${ }^{47}$ A OEA mantêm um sistema de informações sobre o andamento da Declaração Americana sobre o Direito dos Povos Indígenas. (Disponível em: http://www.oas.org/consejo/sp/CAJP/Indigenas.asp. Acessado em abril de 2015) 
57 InterAção

- composto da Corte Interamericana de Direitos Humanos (Corte IDH) e a Comissão Interamericana de Direitos Humanos (Comissão IDH) - sempre esteve à frente no que diz respeito aos direitos dos povos indígenas ${ }^{48}$. Mauro Barelli decreveu cada um destes esforços e registra que a Corte foi pioneira em pesquisar e formar opinio juris sobre o direito coletivo às terras, conforme o caso de indígenas da floresta tropical na Nicarágua, Awas Tingni, em 200149. Siegfried Wiesser registra que a Corte IDH, particularmente a partir do caso subsequente, Saramaka People v. Suriname, de 2008, reinterpretou o artigo 21 (Direito à Propriedade Privada) do Pacto da Costa Rica, originariamente focado em direitos individuais.

No esforço de sistematização de Teresita del Niño Jesús Lúcia Segovia, sobre julgados da Corte IDH, extraem-se dois casos relativos ao direito humano ao desenvolvimento progressivo: Yakye Axa vs. Paraguay e Xákmok kásek vs. Paraguay. Os casos versam prevalentemente sobre o acesso à vida digna, nos termos do Protocolo de San Salvador ${ }^{50}$ : acesso à saúde (art. 10), ao meio ambiente sadio (art. 11), à alimentação (art. 12), à educação (art. 13) e aos beneficios da cultura (art. 14). Na sentença do caso Yakye Axa, de 17 de junho de 2005, reconhece-se que para os povos indígenas, o acesso às terras ancestrais e o uso e usufruto dos recursos naturais que nelas se encontram são vinculados à obtenção de alimento e acesso à agua potável ${ }^{51}$. A autora tece a observação que em nenhum destes dois julgados foi reconhecida a violação do artigo 26 (Desenvolvimento

48 BARELLI, 2010, 962.

49 Nos votos da CIDH: "Among indigenous peoples there is a communitarian tradition regarding a communal form of collective property of the land, in the sense that own- ership of the land is not centered on an individual but rather on the group and its community." (WIESSNER, 2011, 136)

50 Protocolo Adicional à Convenção Americana sobre Direitos Humanos em Matéria de Direitos Econômicos, Sociais e Culturais. Adotado pela Assembleia Geral da OEA, em San Salvador, em 17 de novembro de 1988.

51 apudSEGOVIA, 2012, 227. 
58 InterAção

Progressivo), tendo sido julgados como violação do art. 4.1 (Direito à vida), lido em conjunto com o art. 1.1 (obrigação de Estado de respeitar direitos) ${ }^{52}$.

Em 2006 Jo Pasqualucci publicou na Human Rights Law Review um artigo sobre a evolução dos direitos indígenas no sistema americano de direitos humanos. Analisou casos julgados entre 2005 e 2006 e destacou os casos Moywana vs Suriname quanto à consulta prévia53, Yakye Axa vs. Paraguay e Sawjoyamaxa vs. Paraguay, quanto ao direito à restituição de terras ancestrais ${ }^{54}$ e Aloeboetoe vs Suriname e Massacre of Plan de Sanchez vs Guatemala quanto à observância da lei costumeira e aos valores culturais ${ }^{55}$.

Em 2014 foi publicada a seleção de sete "sentenças paradigmáticas" relativas aos povos indígenas: Mayagna (Sumo) Awas Tingni vs. Nicarágua (2001), Comunidade Indígena Yakye Axa vs. Paraguai (2005), Yatama vs. Nicarágua (2005), Povo Saramaka vs. Suriname (2007), Hitay Nech e Outros vs. Guatemala (2010), Comunidade Indígena Xákmok Kásek vs. Paraguai (2010), Povo Indígena Kichwa de Sarayaku vs. Equador (2012) ${ }^{56}$. Não obstante a importância desse conjunto jurisprudencial, a incursão nestes casos desvirtuaria o foco deste artigo. Em síntese, é possível destacar a importância da opinio juris dos antropólogos e de testemunhas os quais exercem uma função catalizadora para a legitimidade formal na Corte IDH, ao levar aos procedimentos jurisdicionais a cosmovisão indígena na forma argumentativa linear, na semântica e na sintaxe jurídica de Estado. O direito à propriedade comunitária ${ }^{57}$ e à Consulta Prévia, da Convenção

${ }^{52}$ SEGOVIA, 2012, 227-228.

53 PASQUALUCCI, 2006, 291.

54 "In the Yakye Axa case, the Inter-American Court ordered Paraguay, if possible, to return ancestral land to a small group of indigenous peoples who no longer lived on the land." (PASQUALUCCI, 2006, 297 e 289)

${ }^{55}$ PASQUALUCCI, 2006, 289-293.

${ }^{56}$ BRASIL, 2014, 06ss.

${ }^{57}$ BRASIL, 2014, 375. 
59 | InterAção

169 também destacam-se, especialmente no caso em que se debatem as prospecções sísmicas no Equador para fim de exploração de petróleo em território ancestral indígena ${ }^{58}$.

\section{O CONTEÚDO NORMATIVO DO DIREITO INTERNACIONAL DOS POVOS INDÍGENAS}

A Convenção 169, da OIT, sobre Povos Indígenas e Tribais em Países Independentes, de 1989, e a Declaração das Nações Unidas sobre os Direitos dos Povos Indígenas, de 2007, são os dois diplomas que versam especificamente sobre o direito internacional dos povos indígenas.

A Convenção 169, foi adotada na $76^{\text {a }}$ Conferência Internacional do Trabalho, em 1989. O Preâmbulo evoca os direitos humanos na forma da menção à Declaração Universal de 1948 e aos dois Pactos de 1966. A relação dos direitos dos povos indígenas com os direitos humanos na Convenção 169 é tímida se comparada à Declaração das ONU de 2007, tratada mais adiante. A menção aos direitos humanos no preâmbulo da Convenção de 1989 faz parte da consolidação de aproximações entre o emergente regime dos povos indígenas e o regime dos direitos humanos.

A Convenção 169 é composta de partes: I - Política Geral (arts. $01^{\circ}$ ao $12^{\circ}$ ), II - Terra (arts. 13 ao 19), III - Contratação e Condições de Emprego (art. 20), e IV - Formação Profissional, Artesanato e Indústrias Rurais (arts. 21 ao 23), V Seguridade Social e Saúde (arts. 24 e 25), VI - Educação e Meios de Comunicação (arts. 26 ao 31), VII - Contatos e Cooperação além-fronteiras (art. 32), VIII Administração (art. 33) seguidas de Disposições Gerais e Finais. A exposição temática do tratado evidencia o espírito da organização no qual estes direitos

${ }^{58}$ BRASIL, 2014, 443. 
$60 \mid$ InterAção

foram gestados. Seguiu à Convenção uma Resolução referente à Ação da OIT sobre povos indígenas e tribais, de 26 de junho de $1989^{59}$.

Destaca-se neste diploma o art. $1^{\circ}$, relativo ao tratamento jurídico do tema da auto-identidade indígena (ou tribal), a partir de critérios subjetivos-coletivos, ou seja, do reconhecimento pelos próprios povos indígenas sem que Estado ou organização social possa negar ou interferir neste direito ${ }^{60}$. Outro tema que merece destaque é o direito à Consulta Prévia, previsto no artigo $6^{\circ}$ (a): “os governos deverão consultar os povos interessados, por meio de procedimentos adequados e, em particular, de suas instituições representativas, sempre que sejam previstas medidas [...] suscetíveis de afetá-los diretamente." A Consulta Prévia não vincula o Estado ratificante da Convenção 169 no sentido de, caso haja eventual não-concordância dos povos, imposibilitar a medida de Estado. A obrigatoriedade normativa internacional é que o Estado deve realizar a Consulta, de "boa fé" (art. 6 ${ }^{\circ}$ ) quando adotar medida "legislativa ou administrativa" relativa aos povos indígenas. Sobre a aplicação do art. $6^{\circ}$ pelos Estados-Partes, cada sistema jurídico nacional reage de forma autêntica e, por si, decide, no plano normativo interno, sobre a obrigatoriedade da decisão dos povos indígenas ou somente da consulta.

$\mathrm{O}$ artigo $7^{\circ}$ refere-se ao direito dos povos definirem suas próprias prioridades de desenvolvimento 61 . Isto significa participar da "formulação, implementação e avaliação de planos e programas de desenvolvimento nacional e regional que possam afetá-los diretamente." (art. $7^{\circ}$ ). Também “os direitos de

\footnotetext{
59 0IT, 2011, 45ss.

60 "A autoidentificação como indígena ou tribal deverá ser considerada um critério fundamental para a definição dos grupos aos quais se aplicam as disposições da presente Convenção." (Convenção 169/1989, art. 1, 2)

61 "Os povos interessados terão o direito de definir suas próprias prioridades no processo de desenvolvi- mento na medida em que afete sua vida, crenças, instituições, bem-estar espiritual e as terras que ocupam ou usam para outros fins, e de controlar, na maior medida possível, seu próprio desenvolvimento eco- nômico, social e cultural." (Convenção 169, art, $7^{\circ}$ )
} 
61 InterAção

propriedade e posse de terras tradicionalmente ocupadas pelos povos interessados." (art. 14) e de participar da utilização, administração e conservação dos recursos naturais de suas terras os quais constituiriam "salvaguardas especiais" dos direitos dos povos interessados (art. 15).

No âmbito da ONU, os esforços do Grupo de Trabalho sobre Populações Indigenas, particularmente entre os anos de 1981 e 1982 em que se produziu o Relatório Cobo, e a criação do Foro Permanente sobre Assuntos Indígenas (os quais ainda hoje permanecem funcionando paralelamente ${ }^{62}$ ) foram impulsos para o projeto de uma Declaração Universal sobre os Direitos dos Povos Indígenas. Incentivados pela Resolução da Assembleia Geral nr. 41/120, de 1986, a qual instava Estados a se engajarem no desenvolvimento de padrões de direitos humanos ${ }^{63}$, o projeto de 1987 logo foi transformado em uma versão revisada, de 1989, mais conservadoramente formulada que o projeto do Grupo de Trabalho ${ }^{64}$. Em 2006, quando iniciaram as atividades do Conselho de Direitos Humanos, na ONU, uma das expectativas quanto à codificação e desenvolvimento progressivo do direito internacional era acelerar a codificação do projeto de Declaração Universal sobre os Direitos Humanos dos Povos Indígenas ${ }^{65}$.

A Declaração das Nações Unidas sobre os Direitos dos Povos Indígenas, aprovada em 13 de setembro de 2007, pela Resolução 61/295 da Assembleia Geral, em sua $107^{\mathrm{a}}$ sessão plenária, alçou o conjunto dos direitos dos povos indígenas ao patamar dos direitos humanos. Trata-se de uma Declaração, ou seja,

\footnotetext{
62 S. James Anaya reflete que com a criação do Forum, houve preocupação quanto ao fim do Working Group, por uma percepção de redundância. Contudo o Working Group permaneceu como uma instituição viável. (ANAYA, 2004, 221). Hoje em dia o Working Group on Indigenous Populations funciona sob o Alto-Comissariado da ONU para os Direitos Humanos. (Disponível em http://www.ohchr.org/SP/Pages/WelcomePage.aspx. Acessado em abril de 2015)

63 " 3. Urges Member States and United Nations bodies engaged in developing new international human rights standards to give due consideration in this work to the established international legal framework." (A/RES/41/120)

64 MARGADANT, 1992, 174-175.

65 DURAN, 2006, 15.
} 
62 InterAção

não é uma espécie de Tratado sujeito à ratificação. Em 1952, Hans Kelsen, argumenta que a Declaração Universal aprovada na Assembleia Geral em 1948 não seria um acordo que vincularia os membros da ONU e que a Resolução que a adota possui a caraterização de recomendação ${ }^{66}$. Em 1963, J. L. Brierly lecionava que "a declaration is generally used of a law-declaring ou law making agreement, e.g. the Declarations of Paris and of London" 67. Ian Brownlie não menciona definição de Declaração e coloca a Declaração de Paris, de 1856 (talvez a mesma que Brierly menciona), entre os tratados normativos, ou seja, que criam obrigações jurídicas ${ }^{68}$. De fato, a Declaração de Paris de 1856, proibia, por exemplo o aprisionamento de navios mercantes com nacionalidade do inimigo ${ }^{69}$. Sobre a Declaração Universal de 1948, Alfred Verdross escreve que o vínculo com Estados não é jurídico, somente moral, porque a Assembleia Geral não possui competência normativa; a Declaração não possui normas obrigatórias e carece de sanções ${ }^{70}$.

$\mathrm{O}$ artigo $1^{\mathrm{o}}$ da Declaração expressa: "Os indígenas tem direito, como povos ou como indivíduos, ao pleno gozo de todos os direitos humanos", reforçado pelo artigo $2^{\circ}$ relativo ao "direito de não serem objeto de nenhuma discriminação". O artigo $3^{\circ}$, por sua vez, refere-se ao direito à livre determinação, pois que "em virtude deste direito determinam livremente sua condição política e perseguem livremente seu desenvolvimento econômico, social e cultural" (art. $\left.3^{\circ}\right)$. $\mathrm{O}$ artigo $3^{\circ}$ da Declaração ecoa os direitos à auto-identidade (art. $1^{\circ}$ ) e de definir prioridades de desenvolvimento (art. $7^{\circ}$ ) da Convenção 169. No Preâmbulo da Declaração reconhece-se que o conjunto dos tratados relativos aos

\footnotetext{
${ }^{66}$ KELSEN, 2003, 145.

${ }^{67}$ BRIERLY, 1963, 317.

68 BROWNLIE, 1997, 23.

69 KELSEN, 2003, 78.

${ }^{70}$ VERDROSS, 1949, 498.
} 
63 InterAção

direitos humanos "afirmam a importância fundamental do direito de todos os povos à livre determinação". A mais destacada funcionalidade jurídica da Declaração é a consolidação do vínculo da Convenção 169 aos direitos humanos, tendo como fundamento argumentativo a livre determinação dos povos.

A abrangência da Declaração inclui o direito à uma nacionalidade (art. $6^{\circ}$ ), a não serem submetidos à assimilação forçada (art. $8^{\circ}$ ), a pertencer a uma comunidade ou nação indígena (art. $\left.9^{\circ}\right)$, a não serem retirados de suas terras sem o seu consentimento (art. $10^{\circ}$ ), garantias que assegurem a cultura (arts. 11 a 16) e responsabilidades de Estado (arts. 18 a 22). O art. 25 inclui, no plano normativo internacional, elementos da cosmologia indígena: “direito a manter e fortalecer sua própria relação espiritual com as terras, territórios, águas, mares costeiros e outros recursos que tenham possuído ou ocupado [...]". Este artigo, lido em conjunto com o art. 26, que versa sobre o "direito a terras, territórios e recursos" e, particularmente, com o art. 30, que dispõe que não serão desenvolvidas atividades militares em terras ou territórios indígenas sem o livre consentimento destes, coloca o conjunto argumentativo jurídico dos direitos dos povos indígenas em possível choque com interesses de Estados na esfera militar, de exploração de subsolo ou na desapropriação de minorías étnicas.

Povos indígenas é assunto internacional que reúne crenças, instituições, normas, princípios, jurisprudência. Por isso, talvez, pudesse ser afirmada, teoricamente, a existência de um regime internacional dos povos indígenas ${ }^{71}$. A íntima relação do direito dos povos indígenas com outras issue areas, como educação, direitos humanos e meio ambiente, criou laços entre sistemas normativos diversos. Isto significa que o alcance de normas relativas aos povos indígenas ultrapassa o conteúdo normativo da Convenção 169 e da Declaração da ONU de 2007. Um exemplo notável destas possíveis intersecções diz respeito

${ }^{71}$ BARELLI, 2010. 
$64 \mid$ InterAção

à participação de povos indígenas no sistema financeiro ambiental com resultados na Costa Rica, na República Cooperativista da Guiana e no Brasil 72. Neste caso, fala-se na obtenção de créditos de carbono, por parte dos povos indígenas, pela prestação de serviços ambientais, principalmente, conservação ambiental, o que é uma realidade no México, Moçambique e Uganda ${ }^{73}$.

O conteúdo normativo do direito internacional dos povos indígenas foi ampliado, nos termos das possibilidades de fontes, com particular amparo no art. $3^{\circ}$ da Declaração, o qual confere direito à autodeterminação. Em outros artigos da Declaração, como o art. 5\%, o qual confere "direito à autonomia e autogoverno nas questões relacionadas a assuntos internos", ou o art. $6^{\circ}$, com o "direito a conservar e reforçar instituições políticas, jurídicas, econômicas, sociais e culturais" é possível perceber a autonomia normativa dos povos indígenas. Nesta perspectiva, segundo a Declaração, o direito internacional dos povos indígenas é constituído das normas internacionais expressas no diploma tanto quanto normas vigentes nas comunidades indígenas ${ }^{74}$, o que em ampla medida é um direito cultural ${ }^{75}$. Autonomia política significa autonomia jurídica. É possível também falar que estas normas vigentes nas comunidades indígenas são garantidas por normas internacionais pois é possível reconhecer a norma indígena a partir da regra de reconhecimento (no sentido de Herbert Hart) da Declaração. É uma forma de recepção, por parte dos Estados, de normas da cultura ou sociais, na forma de uma validação da decisão tomada nas

\footnotetext{
72 PEREIRA, 2013.

73 MOREIRA, 2011, 158-159.

74 “A poligamia aceita pelos índios Saramacan do Suriname gerou um julgado da Corte Interamericana de Direitos Humanos quanto ao pagamento de indenizações pelo Estado a todas as esposas e filhos, embora o ordenamento jurídico do Suriname não admitisse a poligamia (Caso Aloeboetoe et alia)." (MOREIRA, 2008)

75 Cindy Holder trata de resistências jurídicas ao alcance mais amplo dos direitos culturais dos povos indígenas enquanto direitos humanos: "tendency within diplomacy and international relations, noted most recently in the United Nations secretary general's report to the newly constituted Human Rights Council, to tolerate levels of violations for groups' cultural rights that would be clearly perceived as intolerable were they practiced with respect to other rights." (HOLDER, 2008, 22)
} 
65 InterAção

comunidades indígenas, em regra, segundo um status quo de poder entrelaçado com elementos legitimadores da cosmologia indígena. O conteúdo mesmo das normas indígenas no plano dos Estados normalmente será descrito por cientistas ou estudiosos deste campo, ou seja, por laudos antropológicos.

O que parece caracterizar a estrutura normativa do direito internacional dos povos indígenas é a força vinculante da Declaração, já que a Convenção 169 possui 22 ratificações. O fato de Declaração não se equiparar a Tratado, nos termos da obrigatoriedade da norma, foi um argumento agregado às declarações unilaterais dos países do grupo CANZUS, quando estes países passaram a apoiar a Declaração de 2007. Karen Engle descreve estas incertezas sobre a efetividade normativa do direito internacional dos povos indígenas, e afirma que a Declaração não resolve e sim media múltiplas tensões políticas ${ }^{76}$. Megan Davis em uma avaliação da Declaração cinco anos após sua adoção entende que muita literatura foi produzida sobre o assunto e que o que prevalece na doutrina é que conceito de autodeterminação é interno aos povos indígenas. Afirma que na literatura percorrida, produzida até 2012, há pouca dúvida que o direito internacional tem sido transformador para os povos indígenas ${ }^{77}$.

\section{REFERÊNCIAS}

ANAYA, S. James. Indigenous Peoples in International Law. $2^{\circ}$ edition. Oxford: Oxford University Press, 2004.

AUSTRALIAN HUMAN RIGHTS COMISSION. Aboriginal and Torres Strait Islander Social Justice Commissioner's Submission to the Expert Mechanism

76 "while some argue that the declaration goes beyond other international legal instruments in terms of recognizing indigenous rights, others insist that the declaration adds no new rights but rather is simply a statement of what already exists in customary international law." (ENGLE, 2011, 163)

77 DAVIES, 2012, 48. 
66 | InterAção

on the Rights of Indigenous Peoples. 4th session (11/07/2011). Disponível em https://www.humanrights.gov.au/declaration-rights-indigenous-peoples. Acessado em março de 2015.

BARELLI, Mauro. The Interplay Between Global and Regional Human Rights Systems in the Construction of the Indigenous Rights Regime. In: Human Rights Quarterly, Volume 32, Number 4. Johns Hopkins University Press, November 2010, pp. 951-979.

BORGES, Bethânia Almeida. Pan-Indigenismo: Movimentos Sociais Indígenas na América Latina (1980-2010). Trabalho de Conclusão de Curso de Graduação em Relações Internacionais. Boa Vista: Universidade Federal de Roraima, 2013.

BRASIL. Ministério da Justiça. Jurisprudência da Corte Interamericana de Direitos Humanos: povos indígenas. Brasília: Ministério da Justiça, 2014.

BRIERLY, J. L. The Law of Nations: an introduction to the international law of Peace. Sixth Edition. Oxford: Oxford University Press, 1963.

BROWNLIE, Ian. Princípios de Direito Internacional Público. $4^{\mathrm{a}}$ edição. Oxford: Oxford University Press, 1997.

BRYSK, Alison. From Tribal Village to Global Village. Indian Rights and International Relations in Latin America. California: Stanford University Press, 2000.

CANADA. November 12, 2010. Canada's Statement of Support on the United Nations Declaration on the Rights of Indigenous Peoples. Disponível em http://www.aadnc-aandc.gc.ca/eng/1309374239861/1309374546142. Acessado em março de 2015.

CORTE INTERAMERICANA DE DIREITOS HUMANOS; SECRETARIA NACIONAL DE JUSTIÇA: COMISSÃO DE ANISTIA. Jurisprudência da Corte Interamericana de Direitos Humanos: Direitos dos Povos Indígenas. Brasília: Ministério da Justiça, 2014.

COUNCIL FOR INTERNATIONAL DEVELOPMENT. United Nations Declaration on the Rights of Indigenous Peoples (UNDRIP). Understanding New Zealand's responsibilities under UNDRIP. Disponível em http:/ / www.cid.org.nz/assets/Key-issues/Human-development/ConventionSeries-8-UNDRIP.pdf. Acessado em março de 2015.

CUNHA, Manuela Carneiro da. Os direitos do Índio. Ensaios e documentos. São Paulo: Editora Brasiliense, 1987. 
$67 \mid$ InterAção

DAVIS, Megan. To bind dor not to bind: the United Nations Declaration on the Rights of Indigenous Peoples five years on. In: Australian International Law Journal. Annual, Vol.19, pp.17-48, 2012.

DAVIS, Megan. Indigenous Struggles in Standard-Setting: The United Nations Declaration on the Rights of Indigenous Peoples. Melbourne Journal of International Law, vol. 9, 2008. Disponível em:

http:// www.law.unimelb.edu.au/files/dmfile/download187a1.pdf. Acessado em março de 2014.

DURAN, Carlos Villan. Luzes e Sombras do Novo Conselho de Direitos Humanos das Nações Unidas. In: Sur - Revista Internacional de Direitos Humanos. vol. 03, no. 05, 2006, São Paulo. Disponível em: http:/ / www.scielo.br/scielo. Acessado em março de 2015.

ENGLE, Karen. On Fragile Architecture: The UN Declaration on the Rights of Indigenous Peoples in the Context of Human Rights. In: The European Journal of International Law, Vol. 22, no. 1, 2011, pp. 141-163.

GARZÓN, Biviany Rojas (org.). Convenção 169 da OIT sobre povos indígenas e tribais. Oportunidades e desafios para sua implementação no Brasil. São Paulo: ISA, 2003.

HOLDER, Cindy. Culture as an Activity and Human Right: An Important Advance for Indigenous Peoples and International Law. In: Alternatives 33, 2008, pp. 07-28.

IVISON, Duncan; PATTON, Paul; SANDERS, Will. Political Theory and the rights of indigenous peoples. Cambridge: Cambridge University Press, 2000.

KELSEN, Hans. Principles of International Law (1952). New Jersey: The Lawbook Exchange, 2003.

KYMLICKA, Will. American Multiculturalism and the 'Nations within'. In: IVISON, Duncan; PATTON, Paul; SANDERS, Will. Political Theory and the rights of indigenous peoples. Cambridge: Cambridge University Press, 2000, pp. 216-236.

LE BOT, Yvon. La gran revuelta indígena. México: Oceano, 2013.

MARGADANT S., Guillermo Floris. En camino hacia la Declaración Universal de los Derechos Indígenas. In. Crítica Jurídica. Revista Latinoamericana de Política, Filosofia y Derecho. Nr. 11. México: Instituto de Investigaciones Jurídicas, 1992, pp. 145-182. 
MOREIRA, Felipe Kern. Direito Internacional dos Povos Indígenas: colisão multidimensional de direitos?. In: Meridiano 47. Brasília: UnB, 2008.

. We re only in it for the money: o caso da tutela da floresta de Iwokrama na República da Guiana. Textos e Debates (UFRR), v. 17, 2011, pp. 54-70.

NACIONES UNIDAS. Directrices sobre las cuestiones relativas a los pueblos indígenas. Grupo de las Naciones Unidas para el Desarrollo. Nueva York y Ginebra, 2009.

NEW ZEALAND. Ministerial Statements - UN Declaration on the Rights of Indigenous Peoples - Government Support. April 20, 2010. Disponível em http:/ / www.parliament.nz/en-

nz/pb/debates/debates/49HansD_20100420_00000071/ministerial-statements- -un-declaration-on-the-rights-of. Acessado em março de 2015.

NIEZEN, Ronald. The origins of indigenism. Human Rights and the Politics of Identity. Berkeley: University of California Press, 2003.

OETLER, Anika. Guatemala in the 1980s: A Genocide Turned into Ethnocide? (paper). GIGA Research Program: Violence and Security Cooperation, nr. 19, 2006. Disponível em: http://www.giga-

hamburg.de/de/system/files/publications/wp19_oettler.pdf. Acessado em março de 2015.

ORGANIZAÇÃO INTERNACIONAL DO TRABALHO. Convenção 169 sobre Povos Indígenas e Tribais e Resolução referente à ação da OIT. Brasília: OIT, 2011.

PASQUALUCCI, J. M. The Evolution of International Indigenous Rights in the Inter-American Human Rights System. Human Rights Law Review, nr. 6:2, Oxford, 2006, pp. 281-322.

ORGANIZACIÓN DE LOS ESTADOS AMERICANOS. Los Derechos de los Pueblos Indígenas en el Sistema Interamericano: princípios básicos.

Washington: OEA, 2013.

ORGANIZATION OF AMERICAN STATES. Inter-American Comission on Human Rights. Indigenous and Tribal People's Rights over their ancestral lands and natural resources: norms and Jurisprudence of the Inter-American Human Rights System, 2010. Disponível em http:/ / www.cidh.org. Acessado em março de 2015.

PASQUALUCCI, Jo M. The evolution of International Indigenous Rights in the Inter-American Human Rights System. In: Human Rights Law Review, nr. 6 (July), 2006. Oxford: Oxford University Press. (pp. 281-322) 
69 InterAção

PEREIRA; Isabel Martins. A participação de Povos Indígenas no Sistema Financeiro Ambiental. In: Revista Examãpaku, v. 6, nr. 01, 2013. Disponível em: http://revista.ufrr.br/index.php/examapaku/issue/view/118/showToc

SEGOVIA, Teresita del Niño Jesús Lúcia. Capítulo V. Desarrollo progressivo. In: SERRANO, Andrés González (org.). Sistematización - Jurisprudencia de la Corte Interamericana de Derechos Humanos, Tomo I. Bogotá: Universidad Militar Nueva Granada, 2012.

SHAW, Malcom N. International Law. Fifth Edition. Cambridge: Cambridge University Press, 2003.

UNESCO. 1960. Convenção da UNESCO relativa à luta contra as discriminações na esfera do ensino. Disponível em:

http:/ / www.direitoshumanos.usp.br/index.php/Direito-a-

Educação/convencao-relativa-a-luta-contra-as-discriminacoes-na-esfera-doensino.html. Acessado em março de 2015.

UNITED NATIONS. United Nations Declaration on the Rights of Indigenous People. Disponível em:

http://www.un.org/esa/socdev/unpfii/documents/DRIPS_en.pdf. Acessado em março de 2015.

UNITED NATIONS. General Assembly. Resolution A/RES/41/120 (66/142

Rights of Indigenous People). December 04, 1986. 97th Plenary Meeting. Disponível em http:/ / www.un.org/documents/ga/res/41/a41r120.htm. Acessado em março de 2015.

ECOSOC. Resolution 2000/22, July 28, 2000. Disponível em:

http:/ / undesadspd.org/IndigenousPeoples/AboutUsMembers/ECOSOCReso lution200022/ResolutionE200022.aspx. Acessado em maio de 2014.

GENERAL ASSEMBLY. Resolution A/RES/66/142. December, 192011.

Disponível em http:// daccess-dds-ny.un.org/doc/UNDOC/. Acessado em março de 2015.

GENERAL ASSEMBLY. Resolution A/RES/69/2 (69.2 Outcome

document of the high-level plenary meeting of the General Assembly known as the World Conference on Indigenous Peoples . September 25, 2014.

Disponível em

http://www.un.org/en/ga/search/view_doc.asp?symbol=A/RES/69/2.

Acessado em março de 2015.

UNITED NATIONS. 2004. Secretariat of the Permanent Forum on Indigenous Issues. The concept of Indigenous People. WORKSHOP ON DATA COLLECTION AND DISAGGREGATION FOR INDIGENOUS PEOPLES (New 
70 InterAção

York, 19-21 January 2004). Disponível em

http://www.un.org/esa/socdev/unpfii/documents/workshop_data_backgro und.doc. Acessado em maio de 2015.

UNITED NATIONS. HUMAN RIGHTS COUNCIL. 2007. Resolution 6/36.

December 14, 2007. Expert mechanism on the rights of indigenous peoples.

Disponível em

http://ap.ohchr.org/documents/E/HRC/resolutions/A_HRC_RES_6_36.pdf. Acessado em março de 2015.

UNITED STATES OF AMERICA. 2010. Department of the Interior. Remarks by the President at the White House Tribal Nations Conference. December 16, 2010. Disponível em: https:/ / www.whitehouse.gov/the-pressoffice/2010/12/16/remarks-president-white-house-tribal-nations-conference. Acessado em março de 2015.

VERDROSS, Alfred von. 1959. Völkerrecht. Wien: Springer Verlag.

VITÓRIA, Francisco de. 1532 De Indis. Disponível em http://theahi.org/wpcontent/uploads/2013/10/Francisco-de-Vitoria-on-War.pdf. Acessado em março de 2015.

WIESSNER, Siegfried. 2011. The Cultural Rights of Indigenous Peoples: Achievements and Continuing Challenges. In: The European Journal of International Law, Vol. 22 no. 1, pp. 121-140.

ZIEGLER, Karl-Heinz. 2007 Völkerrechtsgeschichte. 2. Auflage. München: Verlag C.H. Beck. 